\title{
FRUIT CULTURE.
}

SOUR ORANGE STOCK; FERTILIZING AND METHODS OF COMPOUNDING FERTILIZERS; INJURIOUS INSECT PESTS; PARASITES; AND OBSERVATIONS.

\author{
By B. M. LELONG,
}

Secretary of the State Board of Horticulture.

EX OFFICIO HORTICULTURAL OFFICER.

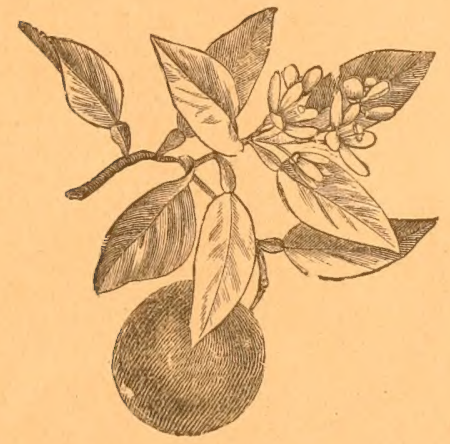

SACRAMENTO :

StATE OFFICE, : : : : : : : J. D. YOUNG, SUPT. StATE PRINTING.

1890 . 



\section{FRUIT CULTURE.}

SOUR ORANGE STOCK; FERTILIZING AND METHODS OF COMPOUNDING FERTILIZERS; INJURIOUS INSECT PESTS; PARASITES; AND OBSERVATIONS.

By B. M. LELONG, Secretary of the State Board of Horticulture.

EX OFFICIO HORTICULTURAL OFFICER.

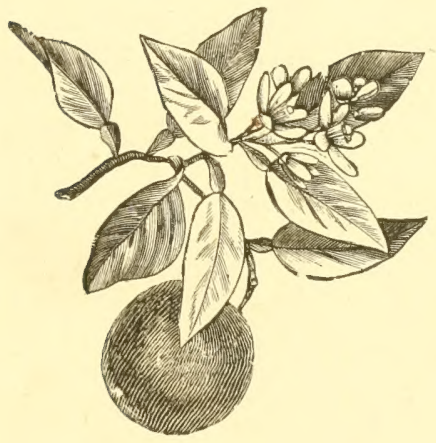

SACRAM E N TO:

STATE OFFICE, : : : : : : : J. D. YOUNG, SUPT. STATE PRINTING.

1890 . 


$$
5^{3} 5^{5^{5}} c^{2}
$$

D. OF D.

A146 301909

$\therefore \vdots \vdots$

$09-29999$ 


\section{PREFATORY.}

$$
\text { San Francisco, Cal., June 10, } 1890 .
$$

During a leave of absence allotted to me at the last meeting of the State Board of Horticulture, I visited several of the Eastern and Southern States in search of information in relation to the fruit industry. This investigation, however, was done without expense to the State.

I left San Francisco early in April, and visited all the largest fruitgrowing districts. I also appeared before various committees in Congress, at Washington, and laid before them all matters therewith intrusted to my care. I hope that the best of results shall be the outcome of this mission.

B. M. L. 



\section{FRUIT CULTURE.}

FRUIT PROSPECTS IN THE EASTERN STATES.-FERTILIZATION AND HOW TO COMPOUND FERTILIZERS.-FLORIDA SOUR ORANGE STOCK.-INJURIOUS INSECT PESTS.-PARASITES AND BENEFICIAL INSECTS.-THEIR INTRODUCTION INTO THE STATE-OBSERVATIONS AND RECOMMENDATIONS.

\section{FRUIT PROSPECTS IN THE EASTERN AND SOUTHERN STATES.}

I visited all the largest fruit districts of Maryland, Delaware, and New Jersey, and found that the peach crop for this year will be almost an entire failure, owing to the heavy March frosts, which destroyed the crops. What fruit was not destroyed is much below the average in quality. This has been a very heavy loss to the eastern peach growers, and has driven many of them out of the business. The trees will have to be cultivated for a year without any production or profit, and the cultivation is very expensive, as commercial fertilizers have to be applied even for the growth of wood. A crop cannot be grown without fertilizers, nor can the trees produce fruit buds for the coming year without it. There is practically no peach crop in the East anywhere, and it will be difficult to supply the demand of the markets with California fruit this year.

The cherry orchards in many districts were full of fruit, but the curculio had stung nearly every fruit, and, in fact, it was with great difficulty that any cherries were found that did not contain from two to eight holes in them. These holes are of a crescent shape, the work of the curculio beetle.

The plum crop is also damaged by the curculio, and, in fact, very little effort is made, on this account, in their culture. The apricot is not grown for the reason that the fruit is also destroyed by the curculio, and the climate is not suitable for its growth. The pear and apple crops will be large; still about 25 per cent will be lost by the ravages of the codlin moth.

This State is the only place from which anything like an adequate supply of green and dried fruits can be obtained this year.

The orange orchards throughout the State of Florida were damaged to a great extent by the heavy frosts in March. They have also suffered by droughts, having had a very dry winter. The rainy season does not begin there until May, and continues through the summer.

Although the trees have suffered considerably, the fruit crop of Florida will be fair, as in many places the frost did little or no damage. These places were mostly where the trees were irrigated. Water is pumped from the lakes for this purpose. 


\section{SOUR ORANGE STOCK.}

There are several varieties of the sour orange tree that are used in many parts of the country as stock for budding purposes. In Florida the "sour orange," or "wild orange," grows in the swamps, and is best adapted to those low, wet lands, as in such lands the sweet orange stock does not live. For this reason this stock is mostly planted. In Florida the sweet orange stock is subject to "foot rot," a disease similar to the "gum disease" prevalent in our State, especially in orchards planted on heavy soil; these, however, are very limited. The "Hammock" lands are planted with the orange and the lemon. These so called "Hammock" lands are low, wet soils, and are always moist. If the sweet orange stock be planted in such soils it certainly cannot live, such conditions being entirely unfavorable to its culture. The sweet orange stock requires good soil and high, dry elevation, while the sour stock requires moist soil, which is only found in these "Hammock" or low lands. The land called "pine land" is of higher elevation and dry. The pines are grubbed out and in their place orange trees are planted. This is what is there termed "high pine land," to distinguish it from the Hammock or low, wet lands.

From observations, I find that the stock does influence the bud to some extent; this, however, is very slight, and is only noticed by experts. One of the greatest objections to this sour stock in those swamps is that it throws up suckers very freely, and as they have to be removed continually, in time the body of the tree presents a curious phenomenon; instead of being smooth, it is very deeply ribbed, and the protuberances at the base swell to immense proportions. This, however, is somewhat avoided by careful trimming. Trees planted on high land, however, do not act thus, and especially where they are properly attended to.

That this stock is very hardy cannot be denied, but whether it will thrive in our dry soils, under entirely different conditions, only time can tell. The orange groves of California are not planted on low, wet lands (we have no such lands), but on the contrary, are planted on dry soil, which is irrigated through the summer. In Florida it rains through the summer months, and the winters are generally dry. In California we have generally no rains throughout the summer, and the winters are mostly wet, this being our rainy season. If irrigation shall take the place of rain, and the trees thus become acclimated, time only can determine.

There is no question but that there is a scarcity of orange stock, but growers can well afford to wait until the value of this stock is proven beyond a doubt, lest they may make a mistake that will require several years to rectify and at great expense. If the stock is really desired for orchard purposes, why not import the seed and not the tree? The seed, from the time of germination, would be grown in our own climate and soil and would receive different treatment, and would certainly be better adapted to the locality where the tree is to be grown. There could then be no risk, at least in introducing injurious insect pests, as is the case where the trees are imported.*

Perhaps the first orchard planted in this State, budded on this sour stock, was that planted at Orange by D. C. Hayward, some ten or fifteen

\footnotetext{
* Nurserymen are now planting the sour orange seed, and very soon plenty of home grown stock can be obtained. Some Riverside nurserymen have already considerable young nursery stock.
} 
years ago. At the Fruit Growers' Convention, held at Los Angeles in March, 1890, this orchard was reported to have died out. I shall soon investigate, in person, whether there is any foundation for the statements made, and this matter will be the subject for a subsequent bulletin.

\section{FRUIT PESTS.}

\section{INJURIOUS INSECT PESTS-GREAT DANGER OF THEIR INTRODUCTION INTO THE STATE, WITH NOTES ON THE SAME.}

There is great danger of introducing various kinds of injurious insect pests on imported trees, and the greatest care should be exercised in that direction. When trees or plants are received from a district, whether it be known to be free from insect pests or not, they should be disinfected and thereby avoid the danger of introducing any new pests that may pass unnoticed.

In order to aid in identifying insects liable to be on imported trees, I give herewith a short description of each, together with the accompanying illustrations:

PURPLE SCALE.

Mytilaspis citricola, Packard.
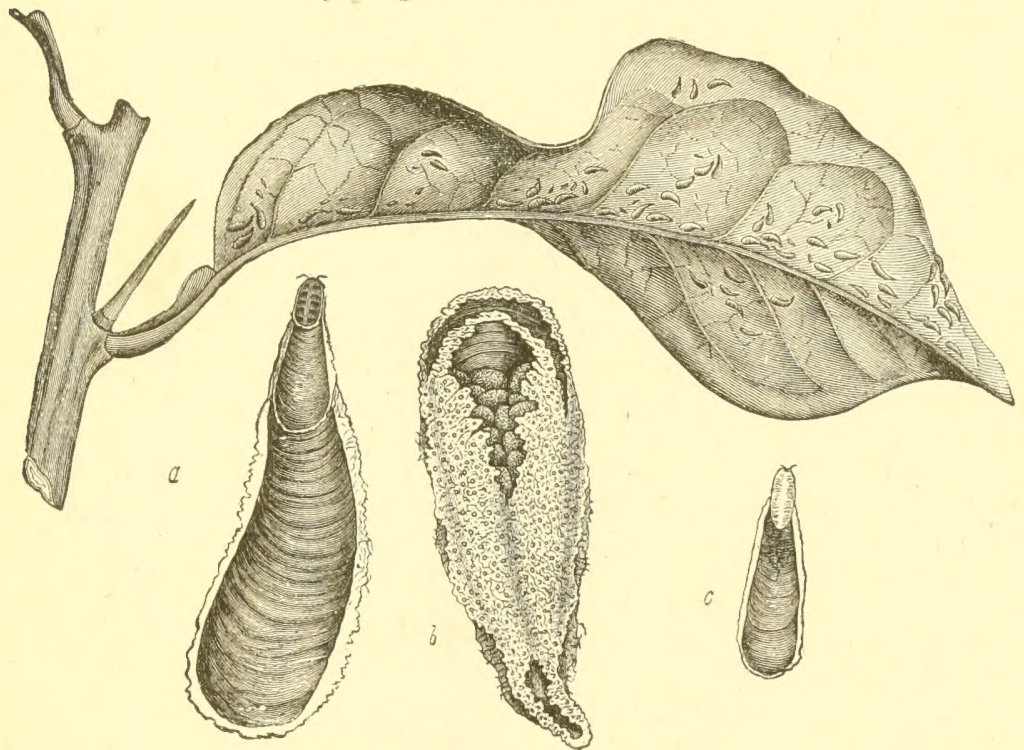

[A purple scale generally found throughout the State of Florida. It resembles $M y t i$ laspis pomorum (oyster-shell scale), which is common in many places on old apple trees. In Florida it is a very troublesome pest. (I) Twig and leaf infested by the scale. $(\alpha)$ Scale of female from above. (b) Same from below, showing eggs. (c) Scale of male. All highly magnified.]

The purple scale (Mytilaspis citricola) is one of the most common species of scale insects found on citrus trees throughout the State of Florida. It was imported into Florida (Jacksonville), in 1855, on some 
lemons sent from Bermuda. Mr. Glover, in mentioning the introduction of this insect, said: "Another coccus was imported into Jacksonville, Florida, on some lemons sent from Bermuda, and as they may perhaps spread in the vicinity, it would be well to draw attention to the insect."*

Since that time it has spread over many of the largest fruit districts, and is very injurious to the tree and fruit, but is most damaging to the fruit, covering the surface thickly, in instances almost hiding the rind from view.

Description.-The length of the full grown female scale is rather more than one twentieth of an inch; it is somewhat pear shaped, and of a brown color; the grub is of a reddish yellow, and furnished with a piercer from its breast. The young have two antennæ, six legs, and two long hairs or bristles at the end of the body. The male scale is not so large as the female, and is formed of a white cottony or parchment-looking substance, constituting a case, with an elevated and rounded ridge in the center, in which a reddish pupa was found. The male larva is reddish in color, and measures not more than one fortieth of an inch in length. The perfect fly is also red, and is furnished with two hairy antennæ, six legs, and has the thorax very large. The two wings are transparent, and the end of the body is furnished with a curved, hard projection.-Glover.

LONG OR GLOVER'S SCALE.

Mytilaspis gloverii, Packard.
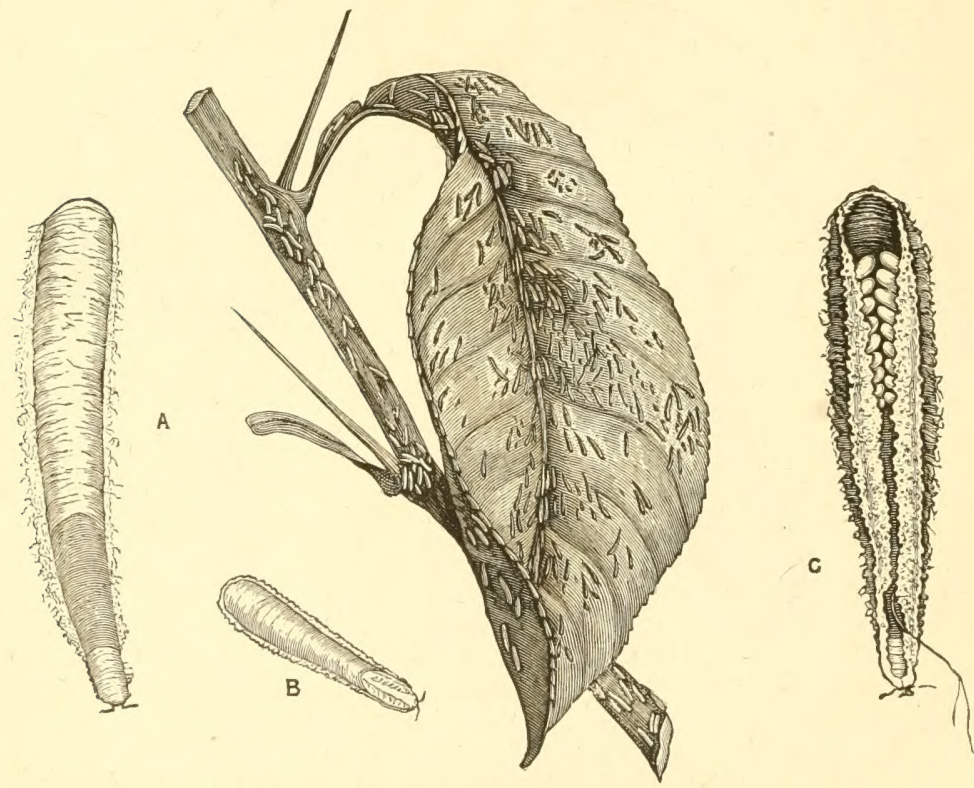

II.

[A light yellow scale, varying to dark brown; resembles Mytilaspis citricola, but is much larger. (II) Branch infested by the scale, natural size. (a) Enlarged. (b) Scale of male, enlarged. (c) Female scale and eggs, enlarged.]

* Report by Townsend Glover, Patent Office, Washington, D. C., 1855, page 119. 
This, like the preceding one, is a very common species on citrus trees in Florida. It infests the leaves and the bark of the trees, and is usually associated with the purple seale (Mytilaspis ritricola). This species is said to have been introduced into Florida about forty years ago, on some trees purchased of a ship in New York from China, and from those trees the scale has spread.

Description.-The body of the female is light purple in color. The scale differs from that of Mytilaspis citricola, in being much narrower; is light yellow, and varying to dark brown. The eggs are white when first laid, but become tinged with purple before hatching, and are arranged in regular rows. The roung larve are purplish, the front of the head and the margin of the body light yellow.

BARNACLE SCALE.

Ceroplastes cirripediformis, Comstock.

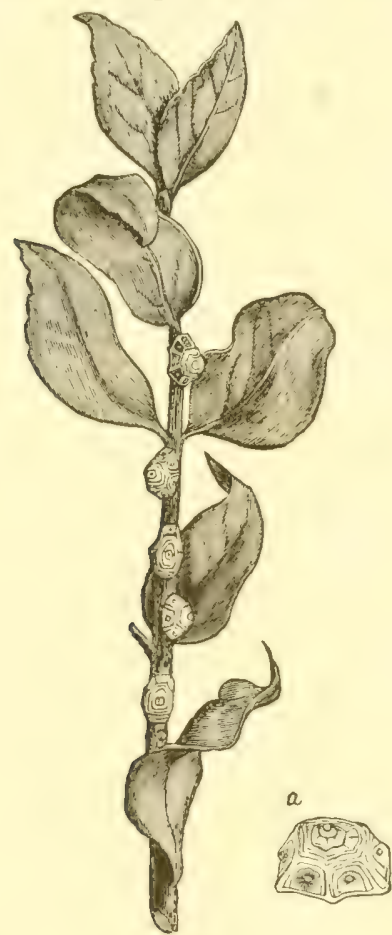

III.

[A small barnacle-like scale. Figure III represents a branch infested with the scales. (a) Female, enlarged.]

This insect is not often met with, neither is it a very troublesome pest. It is not a common species, and is only found in patches. I found this scale on soft wooded plants in gardens and parks, and only saw it on al few orange trees. An Inspector in Los Angeles, however, showed me a number of specimens which he had taken from orange trees imported into that county from Florida. 
FIORYDA WAX SCALE.

Ceroplastes floridensis, Comstock.

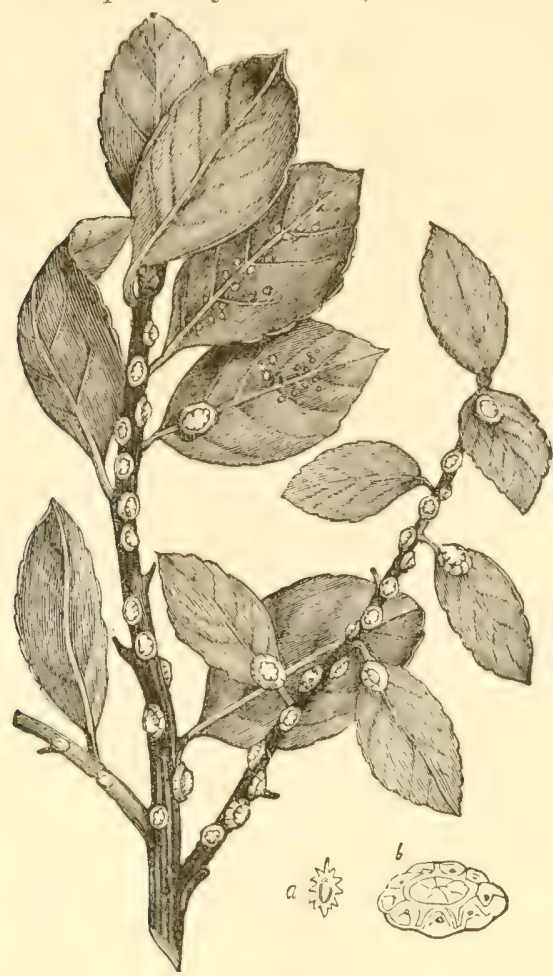

IV.

[A white scale which appears in and throughout Florida. Has not yet made its appearance in this State, and care should be exercised to prevent its introduction; and in order that parties importing trees or plants may be able to identify it, this description and illustration is given. Figure IV represents a branch infested with the scale. (a) Young female. (b) Adult female, enlarged.]

This scale is a very common species, and is found on wild plants mostly. The development of this scale is quite rapid. This insect is no dould indigenous to that state. The trees attacked by it do not suffer as they do by other seales, such as the Aspidiotus and Lecaniums.

\section{CHAFF SCALE.}

Parlatoria pergandii, Comstock.

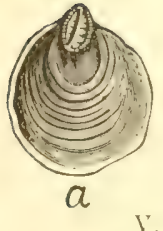

[(a) Scale of female, enlarged. (b) scale of male, enlarged.]

This is perhaps the most common species of scale found throughout the State of Florida. It is mostly found on the trunks and on the large limbs of the trees, covering them thickly, and is but seldom seen on the leaves and fruit. This is a light colored scale, and is more or less circular. When an insect does settle on the fruit it occupies a pit-like depression in the rind. The scale is so near the color of the bark of the trunk and large branches that it is liable to escape unnoticed. 
Aspidiotus ficus, Ashmead.

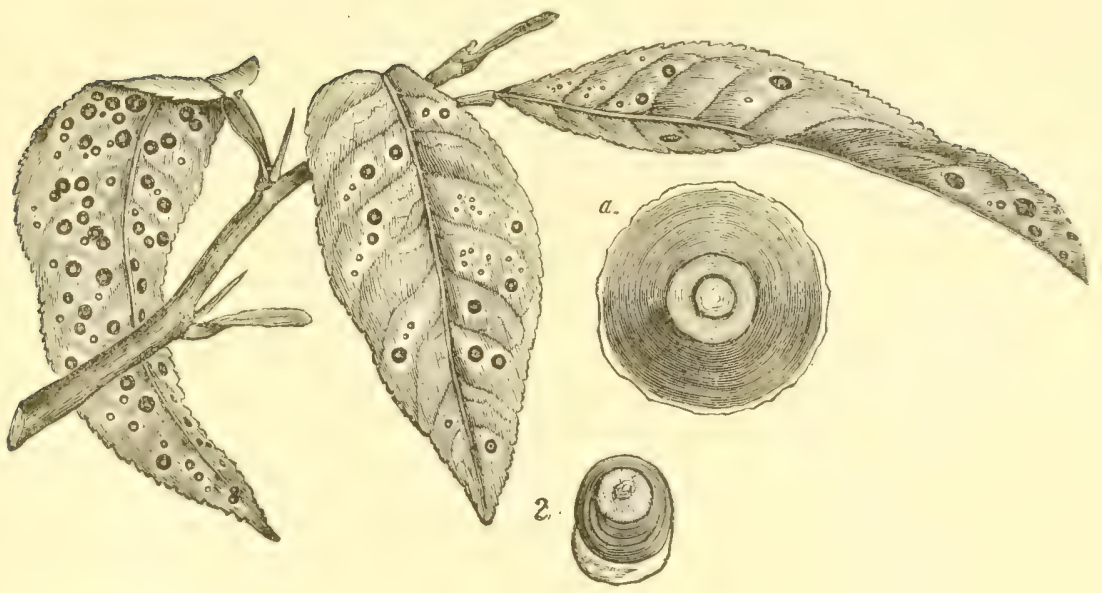

VI.

[A red scale which infests citrus trees in Florida, settling on the young wood, leaves, and fruit. (VI) Leaves infested by the scales. (a) The female scale, enlarged. (b) The male scale, enlarged.]

This scale resembles the red scale of California in form and general appearance, but the scale is not red, as the name implies. The color of the scale is of a dark chocolate color, but the discoloration of the leaves is similar and therefore liable to be pronounced the same. This scale is not widely suread throughout that state and is only found in rerr small patches. The insect is not as damaging as the red scale of California; at least the trees do not suffer as much. The insects do not, as a rule, settle on the wood, but are only to be found on very young and tender wood; they prefer to settle on the leaves and on the fruit. This scale insect was introduced into Florida from Havana, Cuba, in 1874, on a sour orange tree, and since that time it has spread into various orange groves. It had been reported that this scale had been exterminated by a parasite, and also other statements have been made "that its disappearance was due to climatic influences." Upon investigation I found that there was no proper foundation for either statement, although the insect is not found to be as numerous as in the past few vears. The cause of its partial clisappearance was carefully looked into, and after careful investigation, and also from the observations made there by practical growers, I found that its decrease is entirely due to the excessive rains that fall in the summer during their breeding season, and also the trees have outgrown and thrown off considerable of the scale by the application of chemical fertilizers which are applied there very freely. I examined a grove in Orlando, Florida, that at one time had been reported as dying and worthless, due to the ravages of this

* [Note.-In Louisiana this scale attacks the banana plants, and the leaves turn yellow and present a sickly appearance. It was also found upon several varieties of palm and upon the india rubber tree (F'icus macrophylta). In the Botanical Gardens at Washington, this scale is found upon several species of Ficus.] 
scale. The owner assured me, that after doing everything that it was possible to do with remedies, and making but little headway, he concluded to treat the trees at the root; that if in this he did not succeed he would go out of the business. He treated his trees for three years with chemical fertilizers, and a marked effect was seen the year following the first application. After the third year he could find but very few scale. He continued to fertilize, and the result has been indeed wonderful. It is now very difficult to find a live scale anywhere in his orchard. Many of the trees yet bear the mark of the scale that once infested the leares. The trees that were once condemned and declared to be worthless are there to-day, bearing as much and as fine fruit as any other trees that were never affected. The owner not being a wealthy groweralthough in respectable circumstances-manufactured his own fertilizers, avoiding always the too free use of ammonia (after the first year), as this causes the trees to go mostly to wood and leaf growth instead of producing fruit.

RUST MITE.

\section{Typhlodromus oleivorus, Ashmead.}

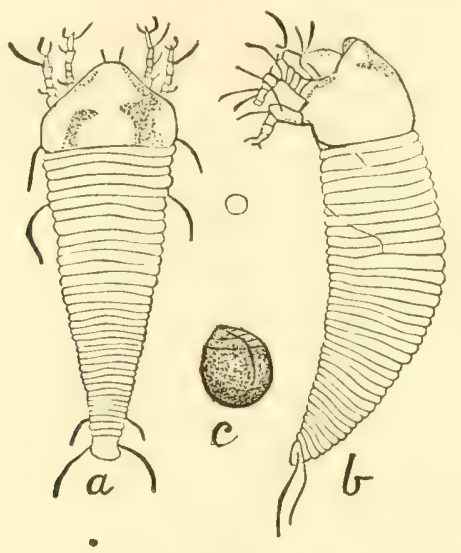

VII.

[ (a) Dorsal vein. (b) Lateral view, enlarged. (c) Egg, enlarged; dot in the center of circle represents natural size.]

This is a very dangerous pest, and one that is difficult to exterminate. This rust mite attacks indiscriminately the various species of the citrus in common cultivation, but has not been observed to feed upon plants of any other genus. It is found upon the lime, lemon, citron, shaddock, higarde, and tangerine; and none of the varieties of the orange are known to be in any degree exempt.-Hubbard.

The foliage of the trees attacked by it present a dry, dusty, and yellowish appearance. This mite attacks the fruit when young, and retards its growth, and when ripe has the appearance of russet apples. This mite was first found on the wild or sour orange trees of Florida, and from those it spread to the orchards, the trees having been transported for cultivation from their native swamps. The mites feed upon the fruit and leaves in droves of many thousands, attacking the former as rapidly 
as they fully mature, and the latter soon after its formation, but mostly after it has fully developed.

This is a microscopical insect, and is not seen with the naked eye. If a leaf or fruit be picked for examination, mites will seldom loe found on them, as all fly away instantly upon being disturbed. The glass must le placed before the object in such a manner as not to disturb them while engaged in feeding upon the leaf or fruit.

\section{NOTES UPON THE RED SCALE OF CALIFORNIA.}

There are two red scale insects in this State which confine their attacks to citrus trees. Prior to 1880 Professor Comstock visited this State and carried on a series of experiments upon the red scale in Los Angeles. The scale upon which he conducted his experiments he identified as the Aspidiotus aurantii of Maskell, and which is the same scale as that found throughout the Santa Ana Valley. This scale was introduced into Los Angeles County on some orange trees imported from Australia, and which were planted at the old Kellar homestead, on Alameda Street. It was introduced into the Santa Ana Valley on some orange trees also imported from Australia, which were planted in the Huntington orehare at Orange. From those trees this scale spread. In San Gabriel a scale insect made its appearance on some trees that were also imported from Australia and planted in the Rose orchard. At that time orange and lemon trees were only imported from Australia.

My attention was called to this latter seale after it began to make its presence felt. Upon examination I concluded it was a different insect from the Santa Ana Valley variety. In 1880 I communicated these facts to Mr. Alexander Craw, of Los Angeles, a very careful entomologist, who visited the orchard and fully agreed with me in my conclusions. In 1Ss1 the late Mr. Cooke, then Horticultural Officer, visited Los Angeles, and I took him to San Gabriel, and after careful examination he also pronounced it different from the Santa Ana Valley scale.

It has been said that "there may be two forms of the same insect." If this be true, why are their attacks on the tree so different? Mr. Klee, in his report as Inspector of Fruit Pests (Biemnial Reports State Board of Horticulture, $1885-6$ and $\left.188_{-}-8\right)$, mentions the fact that the two insects are different, but described the one prevalent throughout the Santa Ana Valley and Los Angeles City as an "Australian type," and the one prevalent throughout the San Gabriel Valley as a "Japanese type." The trees that arrive from Japan are generally infested by this latter species, but previous to 1880 no orange trees were ever imported from Japan. The trees upon which both of these seales came were imported direct from dustralia, and beyond this we know but little; hut all indications point towards Australia as being the home of both these seales.

In $1880 \mathrm{I}$ had the management of a large orange grove in Orange, where I carried on a series of experiments covering a period of three years. In 1883 I moved to San Gabriel, where I carried on a series of experiments covering a period of two years. I was thus able to notice the difference between the two insects. 


\section{DEDUCTIONS.}

From ohservations made, I feel satisfied that there are no "two forms," but that the red scale found throughout the Santa Ana Valley and the red scale found in the San Gabriel Valley are two different and distinct insects. Why? First, because the red scale that is found throughout the Santa Ana Valley attacks the limbs, leaves, fruit, and the trunk of the trees. The one at San Gabriel only attacks the leaves and the fruit. Secondly, in the former the limbs die back; in the latter they do not, as the former covers the bark of the trunk and limbs thickly, and the latter only attacks the leaves and the fruit. Thirdly, the color of the scale of the former is vermilion red; the color of the latter, dirty yellow, and much smaller. The young scale of the former, as soon as a covering begins to form over the insect, is also of a vermilion red, while that of the latter does not differ from the color of the mature scale.

\section{PARASITES AND BENEFICIAL INSECTS.}

Several parasites and beneficial insects have been introduced into California from the Eastern and Southern States, and are now being propagated at three different stations of the Board. Very soon their merits will be known, and, if satisfactory, they will be distributed throughout the State. All parasites and predaceous insects arrived in very good condition. Colonel J. R. Dobbins, of San Gabriel, who received the first colonies, under date of May twenty-seventh writes: "Your several letter's from Florida, Washington, and New York were duly received, as also the box containing the beetles in fine order. I did not disturb them, but merely took the cover from the box and fastened it (the box) among the foliage of the tree, just as I did last year with the Vedalia colonies. I covered two medium sized trees with cheesecloth stretched over a wooden frame, and, as suggested in yours, gave an entire tree to each variety. Each tree was more or less infested with red and black scale, and some aphis. I have looked into these coverings several times, but it is much too soon to expect any development. I had the first lot of Vedalia nearly two months before any increase or work was manifest, and shall not look for anything better in connection with those you sent me. They have been well handled, protected, and cared for, and we must now await the pleasure of dame Nature. My opinion is that no one can form any intelligent ideas as to what may he the outcome of the experiment until sufficient time has elapsed for them to increase and multiply. If they do that, we shall know to a certainty that they have found something to eat and to sustain themselves upon, and measures can then be taken to learn of what their diet may consist."

It had heen reported that the Australian lady bird (Vedalia cardinalis) had died out, and it looked very much that way, from the fact that none could be found until last week (about June first), when several thousand were shipped to all parts of the State from one of the stations of this Board. Colonel Dobbins, under rlate of June first, advises the Board as follows: "Two boxes of Vedalia arrived-one on Saturday, the other on Sunday-and they were in good shape. One colony I located in my own neighborhood, and put the other at Sumy 
Slope. You need not send any more just at present, for if these three colonies do well this valley will soon be well supplied."

\section{FERTILIZING ANL FERTILIZERS-HOW TO COMPOUNI) FORMULAS.}

Having mentioned the use of fertilizers and their wonderful effect upon plant life, I deem it but just to describe the different elements which are the most essential to plant growth, together with the best methods of compounding them, although most of our soils possess the desired elements for plant growth.

\section{POTASH.}

Potash is the element potassium combined with oxygen- "potassium oxide," it is called by the agricultural chemists. Potassium itself is but a curiosity of the laboratory, for it can be kept pure only by excluding all air, and is therefore only to be found in the bottle of the chemist. The name "potash" was given it because it was made in iron pots from ashes.

Potash is a most caustic, biting alkali, dissolving and decomposing all organic structures it comes in contact with. It is one of the most powerful hases; in other words, it is a vigorous, unprincipled chemical thief, seizing upon and alsorking into itself the acids it finds combinerl with various saline compounds. Pure water could not dissolve the potash as it exists in the particles of feldspar and mica that are found in the soil; but, taking carbonic acid from the air, it has the power of dissolving the silicate of potash, leaving the quartz and alumina to form the clays. Caustic lime also has this power. The silica, combined with the potash, and marrying the lime, sets the potash free. In the vegetalle kingdom it is held by plants while in the process of growth, in a soluble state, combined with oxalic, tartarie, silicic, and sulphuric acids. When wood is burned, these acids are decomposed; and, the potash conbining with carbonic acid, we have the common form of carbonate of potash. Potash is not only one of the three essentials for all plant growth, but it is also found in the fruits, vegetables, and grains.

HUMUS.

There is a value in barn manure, in addition to its fertilizing properties. Its bulk has a mechanical effect on the soil, improving heavy soils and lightening the texture of all soils-a fact of especial value to market gardeners in their early crops. Br its partial decomposition, it adds to the mass of dark brown earth which we so especially notice in old gardens, and which goes under the name of humus. Humus is dead vegetable and animal matter in process of decay. In good soil, there is, in a latent condition, potash, phosphoric acid, and lime. Carhonic acid changes these into plant food. Now. humus, by its decay. develops carbonic acid, and so hrings about the decomposition of this latent food. Wet weather favors this action. That carbonic acid has this power to set free plant food in the soil has been proved by the experiments of Professor Stockhardt. Crops take up only a small por- 
tion of the fertilizers applied before the nutrient substances they contain become insoluble. The humus keeps them in a soluble condition, which is an argument for the use of barn manure, or the plowing under of weeds or green crops, in connection with the use of fertilizers. It acts as a sponge to absorb and hold moisture in low, black soils, which are made up of dead vegetable matter in a state of semi-decay, halfway towards coal-a carbonaceous mass of stems, roots, and leaves. Burned, it makes an ashes red, from the presence of iron, having but one sixth the potash to be found in hard-wood ashes. The trouble is, that when dry it takes up water very slowly, and it takes therefore a good deal of rain to moisten it; while, on the other hand, when wet it keeps wet and cold too long for the health of vegetation. Without draining, manure is a waste on such soils.

Humus* holds a great store of carbonic acid, which decomposes the minerals in the soil, setting free potash and phosphoric acid. It also holds latent nitrogen, sometimes as high as 3 per cent, which is six times as much as in average stable manure. This is made plant food by the application of lime or carbonate of potash.

Humus is not in itself plant food. It is not necessary for the yield of heavy crops.

\section{PHOSPHORIC ACID.}

This, the third substance in the three components of a complete fertilizer, is composed of the element phosphorus, combined with the gas oxygen. The four great resources for phosphoric acid are the mineral called apatite, which contains 92 per cent of phosphate of lime, and is believed by some chemists to be the original source in nature from which phosphate of lime is derived; the phosphatic gumos, which are the product of sea fowls, from which the ammonia has been washed out ly the rain; the bones of all animals, and the mineral phosphate rocks, which are the remains of ancient marine animals.

\section{BARN MANURE.}

\section{Its Composition and Fertilizing Properties.}

The latest analysis made of fresh barnyard manure proved to contain the following kind and quantity of elements:

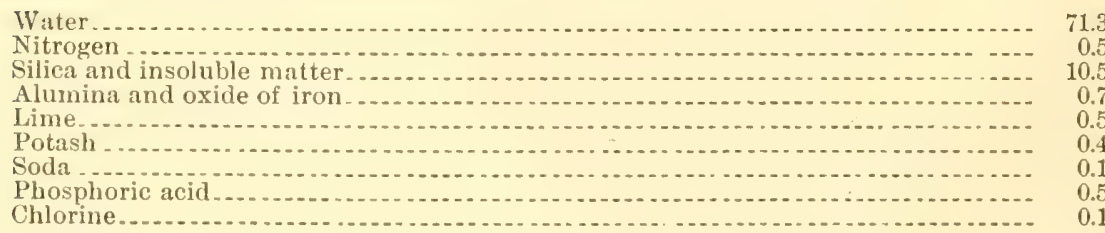

In about 4,500 pounds of fresh stable manure we should have in it 3,208 pounds of water, $22 \frac{1}{2}$ pounds of nitrogen, $472 \frac{1}{2}$ pounds of silica, $31 \frac{1}{2}$ pounds of alumina of iron, $22 \frac{1}{2}$ pounds of lime, $13 \frac{1}{2}$ pounds of magnesia, 18 pounds of potash, $4 \frac{1}{2}$ pounds of soda, $4 \frac{1}{2}$ pounds of sulphuric acid, $22 \frac{1}{2}$ pounds of phosphoric acid, and $4 \frac{1}{2}$ pounds of chlorine. By the composition given it will he noticed that bulk is not what is necessary,

\footnotetext{
*Proîessor Gregory-"How to Compound Fertilizers."
} 
but instrad of bulk the proper clements as fertilizers in a concentrated form are more valuable as plant food than many manures and many so called "commercial fertilizers" a hundred times as bulky. Fertilizers in some form can be made to last like harnyard manure, and feed several successive crops with a single application. For instance, in ashes and bone we have all the elements for a complete manure, when all that is reepuired is to apply an extral yuantity of ashes and a portion of the hone in a coarse state. Ashes are always enduring in their effect, and the coarser hone will be years in decaying and setting free nitrogen and phosphoric areid. To continually apply but a single one of the three clements which enter into the complete manure, and especially if that one should be nitrogen, and for a series of years be in marked excess of the other two, would, in the end, sooner or later, prove that the conclusions often advanced are correct, however faulty they might have been in their reasoning. The fact that the one of the three elements, nitrogen, potash, or phosphoric acid, of which the soil has the least, and which has been repeatedly proven, will always be the measure of the crop. A hundred promds of potash applied would not give a larger yiedd than five prounds (and so of the other two elements), if there is not a proportionate increase of the other elements.

"The right way is to make the most and best manure that is practicable upon the farm, and piece out with such commercial fertilizers as experiments and experience prove profitable. At the same time there are many cases, especially near cities, where everything depends upon gertting the largest and best. (and earliest) yield, where the more exclusive use of chemical fertilizers is advisable." *

Artificial fertilizers are, of course, much more cheaply transported, and unlike barn manure they do not carry with them seeds of weeds into the soil, and as they eontain the fertilizing elements in so condensed at form the whole handling of them becomes much cheaper, where they can be obtained from reliable sources.

"Fertilizers rich in ammonia, Peruvian guano, sulphate of ammonia, etc., should be applied a little at a time and often." †

Clayey soils do not as a rule need so much potash or nitrogen as phosphoric acid. Nitrogen tends to promote leaf growth. Fertilizers applied to poor land produee more effect than when applied to rich land. If the bone in the soil does not all decompose the first year, the nitrogen contained in it goes over with it and is not lost. If but one of the elements is to be used it should by all means be bone, and the finer the bone and the finer and drier the fertilizer the more valuable it is. When the animal matter in bone decays the phosphoric acid in the bone is in a reverted condition.

BONES.

The bones of land animals are composed of the following elements:

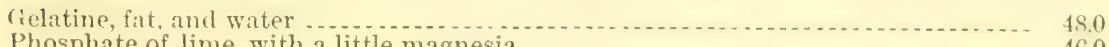
Phosphate of lime, with a little magnesia

${ }^{4}$ iarbonate of lime.....

Potash and soda

100.0

* Says Prolessor Atwater.

+ Professor Atwater, "Fertilization."

Nоте.-The grower should not forget that in using potash or phosphoric acid in any form it never wastes in the soil to any extent, and one application will last several years. 
The gelatine contains from 3 to 5 per cent of nitrogen, and the phosphate of lime (or home phosphate) from 18 to 23 per cent of phosphoric acid. Bonce are brought to the fertilizer manufacturer as the waste of the slaughter-house or butcher shops. Where they have been exposed to the action of the elements bones are found to have lost more or less of their gelatine, and hence are not so rich in nitrogen. The methods of preparing bones for plant food are numerous. By one method the gelatine is saved, and by the other lost. To make the phosphoric in this fully soluble, the bones must be first treated with sulphuric acid, though the results from burning the bones are to reduce the particles to so fine a state as to make them more or less available without the use of acid.

\section{BONE MEAL.}

This substance is made by cracking up and grinding dry bones. These contain, as materials valuable for fertilizexs, phosphate of lime and certain complex substances containing nitrogen. The phosphate is the chief constituent; it forms the frames of the hones, and is what might be called the mineral portion of the same. The other plant food contained in bones belongs to that class of matter from which the plant olotains the material necessary for building-the so called albuminoid sulstance, such as the gluten of wheat, and the legumin of the pea, to which those substances owe their nomrishing and flesh-forming qualities. The more finely divided a fertilizer is the more valuable it is, on aceount of the greater readiness with which it goes into solution. Hence, in detemining the value of a fertilizer, the mechanical analysis is of considerable assistance.

\section{MANUFACTURING SUPERPHOSPHATE.}

In the manufacture of superphosphate, Professor Nichols recommends the following plan: Take a plank hox four fert square and one foot deep. This may be simply water tight, and if so there must be no nails that the acid can reach, for it will eat them out and so make a leak, or it may he lined with lead, all soldering heing done with lead solder. The hox will be large emough to take a carboy of sulphuric acid with the necessary quantity of jhosphate material and water to make about a quarter of a ton of superphosphate. If finely ground bone be used, the result following will be a pasty mass, needing mixing with muck or other dry material to get it in good mechanical condition for use. If, instear of hone, bone llack is used, the result will be a dry mass easily handled. To malie superphosphate, a carboy of one hundred and sixty pounds of sulphuric acid or oil of vitriol ( 60 degrees), three hundred and eight pounds of bone black, and ten gallons of water are required. Having first domned old clothes, and having at hand a little saleratus or some alkali, ready to rub on any spot should by chance a drop spatter. (for where it touches if not immediately neutralized it will char like fire), be sure to first pour in the water, and then the acid; next, slowly add the bone, stirring it all the while with an old hoe of but little value. There will be a great commotion, a great boiling, frothing, and foaming, and throwing off of heat with a suffocating rapor. Because of the suffocating vapor, it is better to do the work in the open air or under an open shed. 
Professor Johnson in his report (Connecticut Experiment Station, 1881 ) gives two methods; the one which he considers best adapted for domestic use of any of the processes involving the use of oil of vitriol, is as follows: Take one hundred pounds of ground bone, such as contains 20 to 50 per cent, more or less, of material coarser than would pass through a sieve, having a one-half inch mesh, twenty-five pounds of oil of vitriol, and six quarts of water. Separate the bone by sifting into two, or if the proportion of coarse bone is large, into three parts, using sieves of one-sixteenth and one-eighth inch mesh. Mix the coarser part of the bone in a cast-iron or lead-lined vessel with the oil of vitriol. When the bone is thoroughly wet with the strong acid add the water, stirring and mixing well. The addition of the water to the acid develops a large amount of heat, which favors the action. Let stand, with occasional stirring, for twenty-four hours, or until the coarser fragments of bone are quite soft, then three grades of bone are used. Work in the next coarser bone and let stand another day or two, until the acid has softened all the coarse bone, or has spent its action; finally dry off the mass by mixing well with the finest bone.

In carrying out this process, the quantity of oil of vitriol can be varied somewhat; increased a few pounds if the bone has a large proportion of coarse fragments, or diminished if it is fine.

Professor Stockhardt, the celebrated agricultural chemist, recommends the following process: From a mixture of sifted wood or coal ashes and earth thrown upon a barn or shed floor from a circular wall so as to inclose a pit capable of containing one hundred weight of ground bone, then make the surrounding wall of ashes so firm as not to yield by being trodden on; sift off the finer part of the bone and set it aside; throw the coarser part into the cavity and sprinkle it, during continued stirring, with three quarts of water, until the whole is uniformly moistened; add gradually eleven pounds of oil of vitriol of 60 degrees strength, the agitation of the shovel being continued. A brisk effervescence of the mass will ensue, which will not, however, rise above the margin of the pit if the acid is poured on in separate small quantities. After twenty-four hours sprinkle again with three quarts of water, add the same quantity of sulphuric acid as before, with the same brisk shoveling of the mass, and leave the substance to act for another twenty-four hours upon each other; then intermix the fine bone previously sifted off, and finally shovel the ashes and the earth of the pit into the decomposed bone until they are all uniformly mixed together.

It will be noticed that the last two processes use half or less than balf the usual quantity of acid allowed for a hundred pounds of bone. The phosphoric acid in finely ground bone can also be made available by the caustic action of the potash in unleached wood ashes.

Professor Nichols recommends the following method: Take one barrel rawbone flour, three barrels dry unleached wood ashes, ninety pounds gypsum, and ten gallons of water; make a heap of the solid materials on the barn floor, and add the water, stirring constantly with a hoe. The result is perfect plant food, containing all the elements plants require in about the same proportions.

Professor Dooling advises a little different method and proportions. He recommends the following: Mix five barrels of finely ground bone with five barrels of unleached hard-wood ashes, and add water sufficient to moisten the mass, and then cover with loam. Leave the heap three 
weeks, adding a little water, if it, on examination, appears to be nearly dry.

\section{WOOD ASHES.}

Wood ashes are our great home source for potash. These are brought into the market from several sources. "Wood ashes," says Professor Goessimann, "have an agricultural value much above their chemical value." Professor Gregory adds that "the principal reason of this is that they contain not only potash but all the elements of plant food except nitrogen, and these in just the same proportion as they exist in nature, with the additional advantage of having them in a very fine state of subdivision."

The wood of different trees differ not only in the proportion of potash, lime, and phosphoric acid in their ashes, but also in the quantity of their ashes in equal quantities by measure of wood.

\section{COAL ASHES.}

Coal ashes contain no appreciable amount of potash; the chief ingredient is silica. They contain also some lime and magnesia. The trace of potash comes from the wood used in kindling fires, and the coal itself. Coal ashes prove of but little value on most soils, beyond making heavy soils more open and supplying silica to land of a much like character, still there is considerable of value in them when used in connection with manure. 

00209730200 